\title{
Education as Framed Sense-Making: A Design Based Research contribution to the theory and practice of play in higher education
}

\author{
Hasse Møller and Signe Smedegaard Skov
}

University College Copenhagen and Copenhagen Technical School

ARTICLE INFO

Article history:

Keywords:

Play

Education

Higher Education

Design

Playful

Pedagogy

\section{Background}

Within the research field of play in higher education, consistent pedagogical frames of conduct are in short supply. The trend to separate theories of learning from theories of play (Walsh \& Fallon, 2019; Whitton, 2018) has dominated and still dominates the field and frequently leads to a lack of coherent pedagogical direction. As we elaborate on in detail in the discussion section, a large portion of current studies on play in higher education view play as a vehicle for learning or learning as an outcome of playing. The present study took off on the proposition to revise and rethink basic theoretical assumptions of play and education. Following Gert Biesta, we asked ourselves: 'Could it perhaps be the case that we have been asking the wrong questions because some of the assumptions from which our questions stem themselves need revision?' (Biesta, 2014, p. 34). From here, our enquiry developed into a theoretical and an empirical question: what theoretical grounds allow us to study higher education pedagogy and play from a coherent perspective? And what practical consequences follow (for higher education and play) from this reconception?

Published under Creative Commons License 4.0

First publications rights: (C) University of Huddersfield Press unipress.hud.ac.uk 
Structure of the paper

To begin, we briefly outline our method of enquiry: Design Based Research. To situate our study in the larger theoretical landscape, we then provide a summary of the theoretical assumptions that our model is built upon. Moving towards specific grounds, we then turn to our empirical data: that shows the effect of the model on a full teacher training course. To conclude, we discuss the empirical implications that led us to rethink our model and summarise what we learned towards our central research questions raised above.

\section{Method of enquiry}

Within the tradition of Design Based Research, we position ourselves as scholars with a transformative agenda (Barab, 2006). Inspired by Thomas Reeves (2006), our hybrid-agenda of both theoretical and empirical enquiry went through phases of domain-specific study, laboratory work, intervention in the field, and reflection. In the domain phase, we learned how a fact-like quality associated with academic content can be substituted with a more toy-like experience when playful approaches are employed in a teacher training course (Møller, 2020). Findings from Møller's study show that this change in significance derives from the different - yet educationally valuable - frame of experience that is engendered through play. Similar to Møller's study, the participatory and explorative aspect of playing seems to hold great value and educational potential. Another key finding from Møller's study is that frames of meaning or significance tend to compete: We experience ourselves as either involved in play, fact-, or tool-production - not all at once. This battle between conflicting assumptions on what learning is, or should be, can also be found in the theoretical field of educational learning (Sfard, 1998). For instance, the battle between understanding learning as acquisition and learning as participation leaves little room for assumptions cutting across the two. Drawing from these insights, we constructed our model around three frames of academic experience, i.e. academic content as fact, as toy and as tool. In search of theoretical resources that could provide an appropriate and coherent theoretical base to our model, we settled on the term sense-making. It connects play and education, being used either directly in descriptions of play (Bateson, 1955; Dewey, 1916, 2005; Henricks, 2015) and education (Biesta, 2014; Dewey, 1938) or indirectly as the purpose of teaching and learning (Hattie \& Yates, 2014; Meyer, 2014). Also, a rapid scoping review (Møller \& Skov, 2021; Tricco et al, 2015) was conducted of the research on play in higher education (part of this review is presented in the discussion section).

In the lab phase, we constructed our model, that is we defined the three frames of fact, toy and tool, and used this structure to plan a course called General Teaching Competence. The goal of the 10 ECTS (European Credit Transfer and Accumulation System) University College course is that students build the competence to 'plan, conduct, evaluate and develop teaching in primary school'. In the intervention phase, the course was taught over a 
period of eight days spread over two months with a total of 25 students participating. Our model informed the progression of each teaching day. The six-hour lesson days would typically begin in the fact-frame, where different strategies for fact-checking, understanding and remembering key concepts and theoretical models were practiced. This was followed by the toy-frame, where planning, exploring, designing and executing formed the primary activities. Typically, in the last hour of the day, the students were invited into the tool-frame, where they engaged in different reflection processes on the theory they had just learned, how that theory informed their actions, and vice versa.

Throughout the intervention phase, we used bricolage as a strategy to gather empirical data. Bricolage invites answers that highlight 'webs of relationships instead of simply things-in-themselves' (Kincheloe 2005, p. 323). A range of different data gathering techniques were used by the researchers to provide a broad and complex sense of the patterns of meaning and involvement within and between the three frames, such as observation and field notes during the course and by recall, pictures, audio- and video-recordings of student activity in the three frames, formative evaluation documents and final evaluations. All students gave verbal consent to the gathering of data throughout the course. The project followed recommended standards of academic ethics (All European Academies, 2017), including full student anonymisation and safe storage of data.

In the first part of the reflection phase, which was initiated on the last day of the course, we invited students to participate in a range of evaluative processes that focused on different aspects of the course such as content, activities, relevance of experience in relation to goals of the course and future application, further study-needs and own engagement and effort. These processes were documented and gathered as empirical data. In the second part of the reflection phase, we analysed all data sources using empirical mapping strategies, inspired by situational analysis (Clarke, Friese \& Washburn, 2018). We placed special attention on relational and positional patterns (Stenner, 2012) to focus on connections between elements and interaction in the empirical data.

\section{Theoretical development and assumptions}

\section{Curriculum, academic content and knowledge}

In the domain- and lab phases we began with what typically forms the centrepiece of educational experience: the curriculum and academic content. Academic content is a sub-category to curriculum and represents more specifically the formal texts and artefacts students meet and interact with (Biesta, 2014). According to Biesta, a vast majority of the study time in higher education settings is spent on reading, remembering and reflecting on texts and theoretical concepts. He states that: 'While thought or reflection must play an important part in this process, they will, in themselves, not result in knowledge. It is only when action follows, 
that the value of both the analysis of the problem and the suggested solution can be established' (Biesta, 2014, p. 38).

In other words, knowledge or 'academic knowing' happens when theory and ideas about the world meet their practical implications and consequences. This shifts our concept of knowledge from the traditional domain of certainty to the domain of possibility, and places action - the practical and experiential application of academic content in situ - at the spine of educational knowledge (Biesta, 2010, 2014; Dewey, $1922,1938)$.

\section{Sense-making}

Following from this perspective, the key responsibility of education is to provide the continual process of sense-making opportunities, gradually changing students and providing new and better opportunities of making sense of the relationship between theory about action as well as application and consequences. Sense-making, which is ultimately a re-formulation of Dewey's concept of experiential continuum (Dewey, 1938), shifts attention to how experience could, and should, be organized and what the different qualities of framed experience should provide. Rather than viewing learning theories as battlegrounds, we view them as describing different frames of educational meaning and involvement, which produce different sense-making opportunities. Professor Anna Sfard states, 'Nowadays, educational research [on learning] is caught between two metaphors... the acquisition metaphor and the participation metaphor' (Sfard, 1998, p. 5). The acquisition metaphor frames the student as recipient, the teacher as provider and knowledge as possession. The participation metaphor frames the student as peripheral participant, the teacher as expert participant and knowledge as activity (Sfard, 1998, p. 7). She concludes that neither one of these metaphors are adequate: 'It seems that the sooner we accept the thought that our work is bound to produce a patchwork of metaphors rather than a unified, homogeneous theory of learning, the better for us and for those whose lives are likely to be affected by our work' (Sfard, 1998, p. 12).

Our theoretical model applies Sfard's idea of patchwork by conceptualising learning as sense-making - a view that can accommodate both perspectives: learning as acquisition, and learning as participation. As we see it, the two learning theories portray the same educational empirical practice but ascribe it different meaning and therefore prescribes different practical involvement (Goffman, 1974). Both perspectives or metaphors of learning provide value - that is, they describe and invite particular qualities of engagement.

\section{Educational framing and play}

When students and teachers engage in processes of sense-making, a frame of meaning is constructed that guides their activity and organizes the educational experience. Møller (2020) showed how the attitude or meaning associated with academic content shifts during play: the meaning or significance of the content changes from more fact-like towards more toy-like. To further this point, Goffman's concept of framing 
(Goffman, 1974) helps us connect play and education as corresponding concepts within frames of sensemaking. Since the concept of framing is central to our theoretical model, we consider it appropriate to provide a brief background to the term. Goffman develops his concept from the basis of Gregory Bateson's theory of play as framing (Bateson, 1955). When playing, we refer to some common generalized experience such as fighting, teaching, dancing, etc., which is then transformed through a degree of 'metacommunication, i.e., of exchanging signals which would carry the message "this is play"' (Bateson, 1955, p. 68). In Goffman's elaboration on framing, he shows that Bateson's conclusion on play applies to most, if not all social situations, where 'a systematic transformation is involved across materials already meaningful in accordance with a schema of interpretation' (Goffman, 1974, p. 45). The meaning of academic content, and how it is communicated, frames the way in which students can and will engage with the content. And Goffman continues: 'Just as it is possible to play at quite instrumentally oriented activities, such as carpentry, so it is also possible to play at rituals such as marriage ceremonies, or even, in the snow' (Goffman, 1974, p. 45). While there will be limits to the educational frame of experience depending on the situation, materials and participants, the point is that any frame of social interaction and materials holds potential for re-framing - and thus, qualitative difference in educational experience and meaning.

\section{Play}

In the theoretical development of the model, we were looking towards conceptualizations of play that aligned with qualities of education and more specifically teacher training: the development of professional judgement (Biesta, 2014) to act tactfully in situated complex contexts of planning, performing and evaluating teaching. Acting tactfully in a complex situation seems to be the general measurement for professionalism. We believe that our conception of play fulfils this criterion. Along with Henricks (2015), Bateson (1955) and Goffman (1974), we identify play as an act of sense-making on the basis of transformed meaning through communication. Sense-making is about finding out what we can do in and to the world, aiming to confront what is known, create new ideas and explore them in new ways of capturing and manifesting meaning. As Henricks puts it: 'Play is a rebellion against the forms and forces of the world. Players confront and challenge 'claims' coming from their own bodies, the environment, the social world, and culture. In those confrontations, they try to manage behaviour their way' (Henricks, 2015, p. 76).

\section{Education as sense-making in three frames}

Our theoretical framework allows for play to be a central part of the pedagogical scope. We call it 'Frame Pedagogy' because it views, talks about and treats teaching in higher education as a practice of framed sense-making. By shifting knowledge from the domain of certainty to the domain of possibility, and by emphasising knowledge as a relationship between theory and practice/action, our conceptualisation 
deconstructs and resolves some of the most apparent dichotomies between theories of learning as well as between education and play. Below is a schematic illustration of the key components in our theoretical model.

\begin{tabular}{|c|c|c|}
\hline $\begin{array}{l}\text { Fact: Academic content is } \\
\text { framed as factual substance } \\
\text { to be acquired and } \\
\text { transmitted to the student. }\end{array}$ & $\begin{array}{l}\text { The student participates as novice } \\
\text { recipient, the teacher as provider, } \\
\text { and academic content as } \\
\text { possession. }\end{array}$ & $\begin{array}{l}\text { In the frame of academic content as fact, we } \\
\text { invite the students to accept and acquire } \\
\text { the knowledge presented. The students } \\
\text { must "wrap their heads around" theory and } \\
\text { concepts and get it 'right'. }\end{array}$ \\
\hline $\begin{array}{l}\text { Toy: Academic content is } \\
\text { framed as toys to be played } \\
\text { with. }\end{array}$ & $\begin{array}{l}\text { The student as player/creator, the } \\
\text { teacher as co-player/creator and } \\
\text { facilitator, and academic content as } \\
\text { materials for playing/investigating/ } \\
\text { experimenting/creating. }\end{array}$ & $\begin{array}{l}\text { In a frame of academic content as toy, we } \\
\text { invite the students to engage with the } \\
\text { knowledge as an explorative quest, one that } \\
\text { scans and challenge the rules and the } \\
\text { rightness of the content presented. The } \\
\text { students surmounts and try out the } \\
\text { properties and possibilities of the toy. }\end{array}$ \\
\hline $\begin{array}{l}\text { Tool: Academic content is } \\
\text { framed as possible and } \\
\text { assessable tools for future } \\
\text { application and action within } \\
\text { the setting of a professional } \\
\text { teacher. }\end{array}$ & $\begin{array}{l}\text { The student as professional and } \\
\text { experienced judge of the future } \\
\text { worth and usefulness of academic } \\
\text { content, the teacher as neutral } \\
\text { facilitator and academic content as } \\
\text { tool. }\end{array}$ & $\begin{array}{l}\text { In a frame of academic content as tool, we } \\
\text { invite the students to reflect on their } \\
\text { experiences, make up their own minds and } \\
\text { qualify their own and collective connections } \\
\text { between theory, action, consequences and } \\
\text { future actions. The students think and } \\
\text { reflect with and on experience. }\end{array}$ \\
\hline
\end{tabular}

\section{Empirical analytic insights}

We now turn to the testing of the model as a pedagogical model for structuring, planning and conducting the course. Specifically, the students were engaged in all three frames every day, starting in the fact-frame, then the toy-frame and finishing in the tool-frame. While each frame was presented as a unique mode of engagement and meaning, with clear brackets in space and time (Goffman, 1974), the model also had an underlying pedagogy with respect to the overall educational situation. As exemplified in the following, the structure of the model and our explicit mention of 'pedagogy by design' communicated meaning on a metalevel (Bateson, 1955). We coin this: The significance of pedagogy as a performative framing of meaning and involvement.

\section{Pedagogy by design}

When we present the course and the three frames to the students, we communicate on a literal level: we talk about intentions, frames, experience, play and sense-making. On a relational and meta-communicative level, we signal meaning and a pedagogical norm through our interactions with students, knowledge, learning, play, ourselves, etc. In that sense, we signal that we wanted to create an informal space of experimentation, play and relevant sense-making. In the example below, the two lecturers sit on each chair in the middle of 
the room. The students await what is coming. All they have been told is that we will try an experiment of improvised interviewing each other on how it is to be a teacher. Signe starts off by asking Hasse:

'So, why was it, that you wanted to become a teacher?' ‘Well, for me it has always been about curiosity for how we learn stuff. And it is so hard to figure out when you are out there!' [the students laugh]. 'For instance, I had a 6 th grade in music for a full year for one hour each week. And I never came around to creating a setting, where deep learning or progression could take place. I basically shouted and managed behaviour for a full year' [students laugh again] (Excerpts from audio recording of the beginning of the first day).

The following concepts clarify what is meant by a performative framing of meaning and involvement.

Deconstruction: We present the model of Frame-Pedagogy in detail on the first day of class and support it through pedagogical argument and comparison to other approaches to educational practice. The relevance of play as a frame of experience is both argued for and exemplified.

Informality: We begin the first day by performing a lecturer interview with each other, where we, unscripted, tell stories about living teacher lives and the complexities surrounding it. We invite students to tell their stories about how and why they are studying to be teachers as well as what worries them in relation to the practical world of teaching. As a general principle, we encourage students to ask questions and when asked, we would often pause and spend time on these questions.

Knowledge as possibility: By implying that playing is legitimate in this educational setting and, in fact, is a relevant way of making sense, the students are invited to join a practice of experimentation and possibility. To sustain this joint sense of transformation in meaning, we take part in the students' planned sequences as explorers: we create games with them and participate in humorous talks in and out of class. We encourage wacky ideas and try out our own ideas that would sometimes go wrong, only to be used as healthy examples for reflection.

Enthusiasm: Our motivation to develop the design is based on our deep professional belief in and experience with play as a valuable and worthwhile educational frame of experience. We encourage humour and play through being light-hearted, leaving room for spontaneity and having a laugh when laughing is called for. While these points, to some, might raise questions of bias and subjective interpretation, it is worth the risk so as to acknowledge, exemplify and manifest the importance of the teacher relative to the design, and the design as a performative category.

Clear signalling: Every frame is clearly marked by brackets in time and space. We articulate that we now enter the Fact-frame and what purpose and involvement is expected. When the activities are over and done with, this is marked through articulation and shifts in activity and tempo. 


\section{Sense-making in three frames}

From video-, audio- and observational data, different qualities of sense-making processes were observed both within and across frames.

\section{Academic Content as Fact}

In the fact-frame, sense-making, understood as students making sense of the meaning of words, texts, models and concepts in a pre-defined way, was observed as foregrounded. To grasp or 'wrap their heads around' a theory of inclusion, for example, was not necessarily an easy and concrete task. Acquiring factual knowledge, from a Dewey'an viewpoint, would be conceived as an interpretative quest. By the students mirroring their interpretations on each other, sense-making thus became a phenomenological quest for understanding 'the thing as it is'. While recognizing the relational ontology of experience (Clarke et al, 2017; Dewey, 1938; Stenner, 2012), it is possible to view certain elements and their position in the situation as foregrounded in the events of sense-making (Stenner, 2012). We define this foregrounded act of sensemaking through the combinational term 'Student-thing'. In the picture example below, the students had read the Promulgation of the law on the Primary School, learning goals for the subject course Danish, the didactical theory of Wolfgang Klafki, and six praxis-domains by Dietrich Benner. The exercise was called 'recall and connect', where the students in groups collectively should recall what they had read (they were all allowed to cheat and use their books) and write it down within the timeframe of 10 minutes.

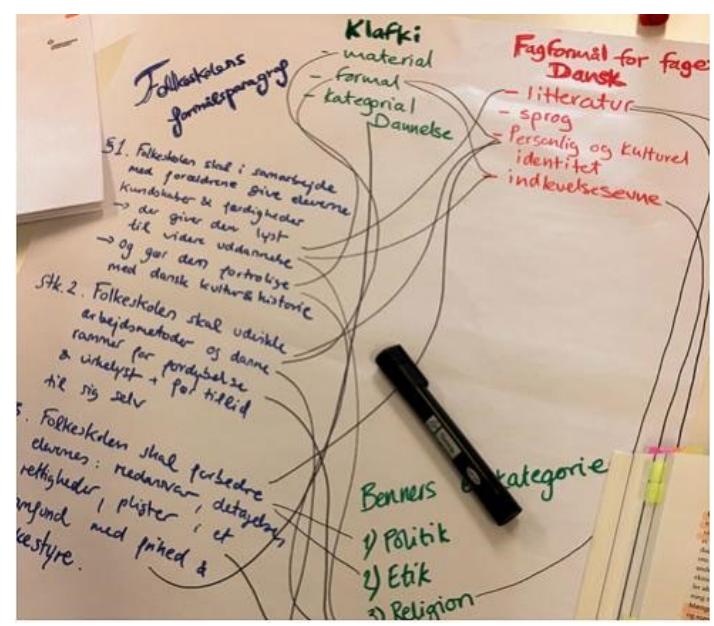

Then they were given 10 minutes to look for connections between knowledge domains. The purpose of the activity was to fact check their understanding through social interaction and negotiation, and to understand how different aspects of practice, as well as didactics and basic school law were connected. 
In the Toy-frame, sense-making revolved around the relationship between things, actions and consequences. The data showed two foregrounded combinations of sense-making; Thing-Action and Action-Consequences. Within the Toy-frame, the students would both plan and perform teaching sequences. In the planning Thing-Action events - the understandings of concepts and theory would act as centrepieces in creating and planning for action. The students tried to imagine or develop hypotheses on the relationship between a given theoretical concept and its possible properties. When their planned sequences were set in motion, the focus of sense-making shifted towards real-time reflection in action (Schön, 1991) or Action-Consequences, trying to manage and make sense of how fellow students and lecturers reacted to their sequences and how appropriate counter-actions could be performed.

One example of sense-making in the toy frame is from the second day of the course. The students were given a paper on how to open up or present a given topic or subject matter. They were then handed an onion to use as an entrance to a subject. They planned in groups a brief 10-minute sequence of teaching (as teachers $=$ T) and performed the sequence with the other students and lecturers as the primary school students (PS). Below is an excerpt from an audio recording of the sequence performed, where we stand in a circle and one of the students introduce the onion:

T: 'Do you know what this is?' PS: 'Yeah, it's an onion.' T: 'Yes, it is but actually, it is our selves. You see, this is actually my hair (pointing to the outer layer of the onion), and if I peel off one layer, what do you think will appear?' PS: 'Thoughts, maybe?' T: 'Exactly, and what would appear if we peeled a layer from you? What is beneath?' PS2: 'Firstly, I would tell you about my age and where I am from... next layer would perhaps be about my family and interests.' T: 'In psychology, some suggest that the onion reflects how we as humans are constructed...' (Excerpt from audio recording).

The example shows that the group has chosen to use the onion as an entrance to the subject of psychology and theory of self. When the student as a teacher asks questions to the students, gives suggestions to perspectives and invites the students into the dialog, it creates a situation of action-reaction, adjusting the teaching to the responses, reflection in action and getting a sense of how the relation between teacher and student is enacted in real-time. Other groups used the onion to introduce the subject matter of physics and mathematics. This variation in themes gave basis for later reflections on the many ways of relating subject matter to the world as well as different ways to engage students in the process. 


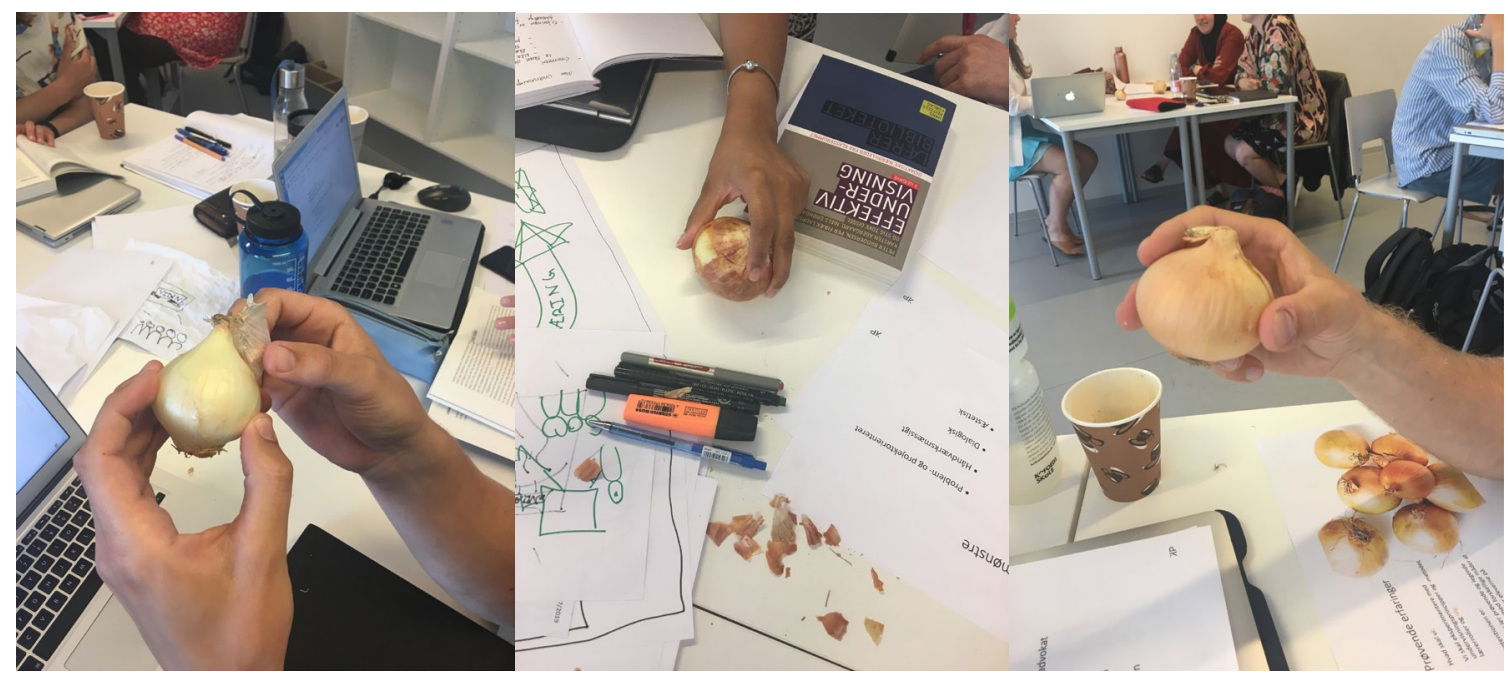

\section{Academic content as Tool}

Lastly, sense-making shifted towards what we term Experience-Consequences in the Tool frame. Here, sense-making was about reviewing both theory and practice, action and reactions in relation to its practicality and usefulness. It is worth noting that the many acts of playing, the informality of the classroom, and the continuous deconstruction of "certainty" set footprints in the students' attitude towards the Tool frame. In no way unserious, rather curious, light-hearted and enthusiastic.

We used a range of different approaches to the reflections on academic content as tool for reflection and action as teachers. One was called "pizza-reflection", where students would draw a circle, then draw eight slices and write one concept or experience from the day on each slice. We asked the students to prioritize what seemed most useful by "eating" or scratching over the least important ones, one at a time. This approach connected the three frames from a pragmatic viewpoint, where facts and experiences and student's personal insights with acting out theory were reflected on and related to future actions as teachers. Below is an excerpt from three students' discussion about which ones to scratch out and which to keep:

Student (S1): 'Different activities I think that one is quite important...' S2: 'I think I would scratch participation, because it relates to different ways of engaging students' S1: 'You are right.' S2: 'Great, that was easy.' [they laugh]. S3: 'It might become difficult with the next ones.' S2: .Okay, so we have "incorporation of real-life surroundings when teaching" and "realistic correlation between subject matter and reality".' S3: 'Yeah, but I think "cooperation with the parents" is really important too. I think this might be something that I need to keep constant focus on as a teacher, remembering to keep a close dialogue on how their kids, my students, are doing in class.' (Excerpt from audio recording). 


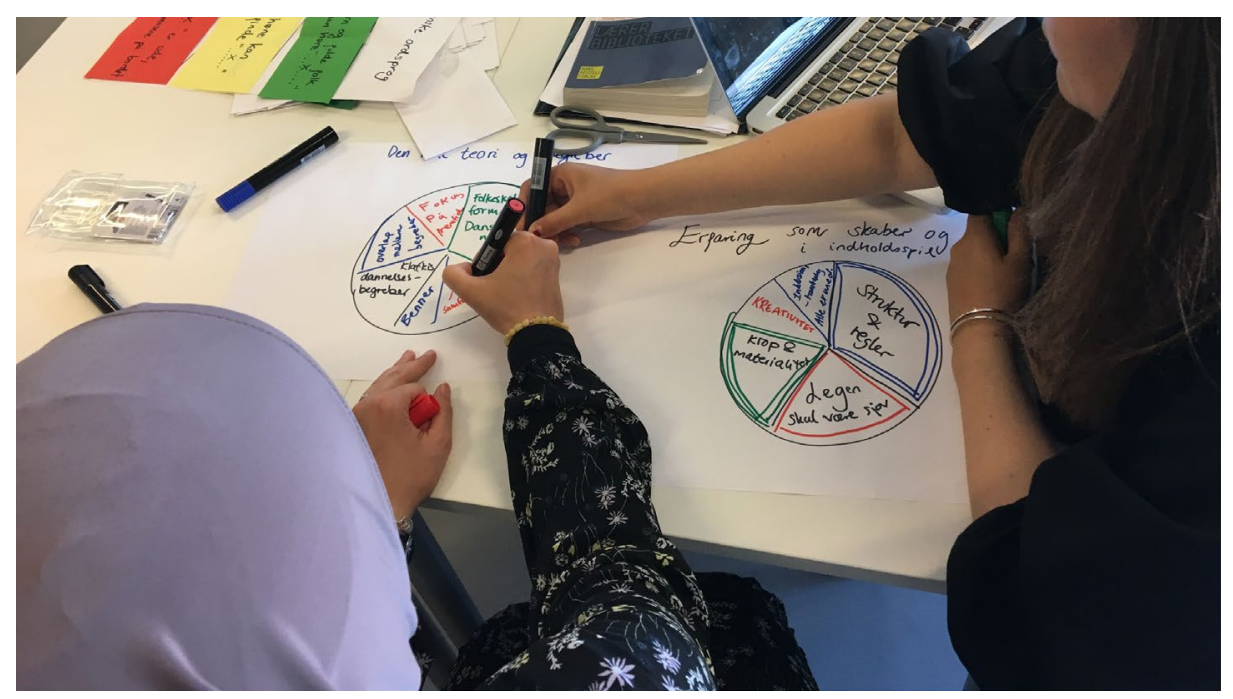

The tool-frame could in some sense be termed the pragmatic frame, and the students connect through reflecting on action to the pragmatic use of both theory and experience. After exercises such as pizzareflection, we would talk in plenum about the different choices and concepts the students had highlighted. Usually the students found great inspiration and insights from mirroring their own preferences to the other students.

To summarize: our observational data shows that the design and the way we performed it had an impact on the collective attitude towards meaning and involvement. A pedagogy of deconstruction, informality, enthusiasm and knowledge-as-possibility seemed to cut across the three frames and coloured interactions towards more playful and experimental involvement. We saw how the three frames provided different sense-making opportunities that foregrounded certain elements. In the fact-frame, sense-making was especially revolving around student-thing. In the toy-frame, sense-making was focussed on thing-action and action-consequences. In the tool-frame, experience-consequences became the foregrounded element to be made sense of. In the following, we turn to the student accounts, emphasising how the students perceived the different frames as well as how educationally valuable they found the course.

\section{Student accounts}

In the final evaluations of the course, we invited the students' accounts on the overall educational quality of the course. We asked the students to write down their accounts in a semi-structured interview-form. Two patterns or storylines emerged and are conceptualized as: Theory-practice and Variation.

\section{Theory-practice:}

The following student quotes help clarify what we denote 'Theory-Practice':

'That theory has become easier to understand because we are constantly tied to an activity and an example of how it can be done. The concepts presented have made tremendous sense because they have been quickly translated into "teaching contexts".' 
'Theory may sound absolutely amazing, but very difficult to implement in reality.'

'Specific practical experience where our (lack of) teaching skills came into play and were trained and developed.'

'... it's nice to have a hook on which to hang theory - so that it can constantly be translated into reality and not just theory for the sake of theory.'

'It is good when it comes to acquiring general knowledge and then defining how that knowledge is applicable in practice.'

'It has been really cool that teaching time has been devoted to practice. That the theory has become easier to understand because we are constantly tied to an activity and an example of how it can be done.'

'It has made me gain a lot of practical experience in a relatively short course. It has put the concepts into play.'

These student quotes can all be interpreted as making relevant experiences associated with both understanding theory and developing practical know-how. They strongly indicate a great deal of experienced integration of theory and practice in a way that is perceived to be relevant.

\section{Variation:}

The term variation was used either directly or implied indirectly by the students. The quotes below illustrate this:

'I think it has been great! Everything was taken care of, there has been good variation, good atmosphere, you have communicated well and everything has felt relevant.'

'I think the variation between the different days has contributed to my learning.'

'There has been a good mix and variety between the different activities and it has been good.'

'In general, really good I think. There has been good consistency between activities and academic content, and it has been good that there has been a lot of variation.'

'There has been a really good variety of classic "chalkboard teaching", problem solving, reflection and presentations.'

'Great that the first two weeks were so varied and up-tempo. I felt like I had to stand on my toes to keep up. It was very motivating.'

'I have experienced the course as varied. The dynamics between the activities have forced me to follow and participate and I need that.'

The student accounts suggest that the quality of variation in activities is related to the variation in frames that we provide for them to learn from, within and through. It is also noteworthy that the combination of frames, not one frame in particular, seems to sustain the perceived (high) educational outcome. 
These insights led to a revised version of our design Frame-Pedagogy 2.0 as illustrated below.

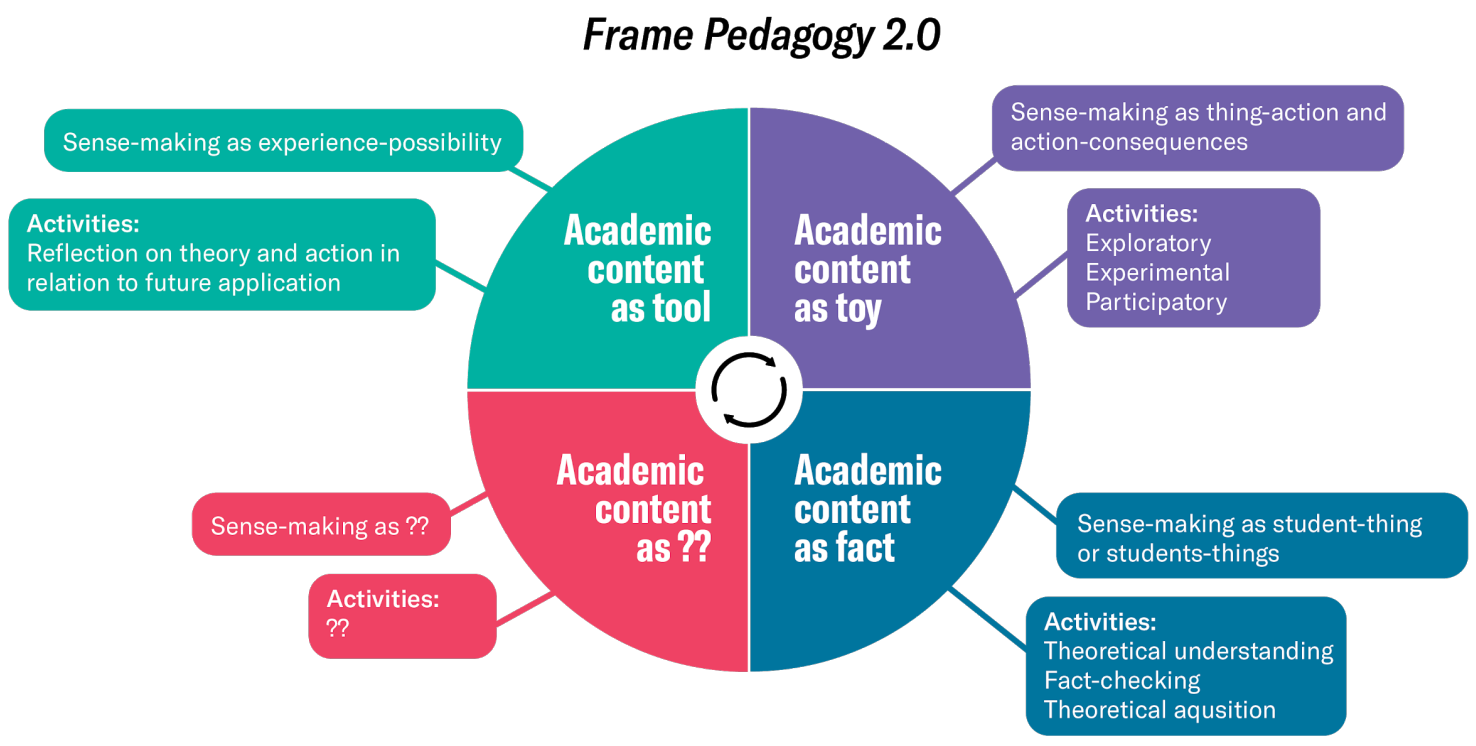

Firstly, instead of treating the model as a progressive model, we now consider it more dynamic and circular. While the order of fact $=>$ toy $=>$ tool appears appropriate in light of our empirical data, we encourage exploring a different order of frames. We furthermore added clues to the kind of sense-making events that are likely foregrounded within the frames as well as clues to the kind of activities that support these events. It is important to note the teacher/lecturer as a key figure or agent in performing and creating these frames. Materials and context should also be viewed as such.

Recognizing the dynamic and contingent nature of creating and performing pedagogical models and frames, we view our model as work-in-progress just as we view general pedagogical theories and models as such. Thus, we have added a fourth frame with a question mark, to recognise the situated nature of needs and purposes in most, if not all, frames of educational experience.

\section{Discussion}

So far, we have outlined the theoretical and empirical base of our model. In this section, we discuss and elaborate on the implications and applications of the design in relation to recent studies on play in higher education. We would have preferred to relate our study more specifically to studies on play in teacher training programs but since the research is lacking, we resort to a more general search for studies. Our scoping review identified two major pedagogical approaches to play: one portraying play as separation and one portraying play as correspondence. We provide a brief summary of our findings below. A more detailed account can be found in Møller \& Skov (2021). 


\section{Play in Higher Education}

As part of the domain phase of designing Frame-Pedagogy, we conducted a rapid scoping review of the literature on play in higher education. Scoping as an approach to reviewing literature is an appropriate strategy to identify research gaps and illustrate theoretical potential (Munn et al., 2018). Our initial intention was to qualify the theoretical empirical base of our design development process. However, in the process, we decided it to be important to situate our model and our considerations within the current field of play in higher education. All the studies found can broadly be termed intervention studies, where play and playful approaches are explored in different educational settings. No studies with specific attention to teacher training in Denmark were found. We analysed the studies with special attention to the meaning ascribed to play, and came to organise the research we found according to whether it portrays play as separate (different) from, or corresponding to (equally fit as) 'standard approaches' in higher education pedagogy.

\section{Play as separation}

A majority of the studies found in the review interpreted play or playful as a method and what we term play as separation (Goodwin, Low, Ng, Yeung, \& Cai, 2015; Koupf, 2017; Liang, 2015; Majgaard, 2014; Pánek, Pászto, \& Perkins, 2018; Phillips, 2015; Suoto-Manning, 2011; van As \& Excell 2018; Varvarigou, 2017). Play as a method for learning or sense-making appears in terms on play such as 'methodologies (that) deepen the acquisition of academic skills' (van As \& Excell, 2018, p. 1), 'playful methodologies' (Pánek, Pászto, \& Perkins, 2018, p. 321), 'playful acquisition' (Liang, 2015, p. 169) or play to 'be used as a tool for learning' (Majgaard, 2014, p. 273). While there are multiple nuances embedded within these studies, play serves first and foremost as a vehicle for promoting learning or motivation for learning and is employed when useful in relation to a given learning target. Play is not regarded as valuable educational experience in itself, or as a healthy educational attitude towards content. While we in principle agree on the potential educational benefits of using play types and playful structures as supportive structures for learning, we find that this tends to position play as a tool for fixing problems of learning (Henricks, 2015). Relating this pedagogical premise to the findings from our study, several relevant educational aspects of play are left out. Firstly, our theoretical construct and empirical findings support the more broadly stated claim, that play should be considered a collective attitude towards content that supports and promotes relevant frames of experience. Secondly, while our students worked in different frames of meaning and involvement, a playful attitude emerged that translated "boring drilling exercises" into games of facts. Planning and executing teaching sequences translated into playful re-doings which again translated into relevant student insights into how theory informs practice. In other words, we believe that reducing play to the role of midwife for learning 
blinds us to the more significant educational values play holds, of which we have presented several examples.

\section{Play as correspondence}

Play as corresponding with, rather than being in service of, education, was found as another pedagogical way of interpreting and ascribing meaning to play (Bjartveit \& Panayotidis, 2017; Bogers \& Sproedt, 2012; Carlson \& Clay, 2010; Nørgård, Toft-Nielsen, \& Whitton, 2017; Thorsted, Bing, \& Kristensen, 2015; Walsh, 2015; Whitton, 2018). Indicators of this understanding were seen in views on play as 'a life-phenomenon with its own value' (Thorsted, Bing, \& Kristensen, 2015, p. 66), deepfelt engagement (Bjartveit \& Panayotidis, 2017) or as 'deeply rooted' in human ways of dealing with the world (Bogers \& Sproedt, 2012, p. 76). In Bjartveit and Panayotidis' study of dark play in an online course, they co-created an imaginative world with their students to co-experience the phenomena of 'dark play' (Bjartveit \& Panayotidis, 2015). Instead of reading about dark play, they played. This approach turned play away from the means to the ends, positioning and encouraging playing as an experience corresponding with educational values. In Nørgård, Toft-Nielsen and Whitton (2017), play is theoretically aligned with a view on education that 'recognises the importance of openness, curiosity, risk-taking and failure in learning' (p. 2). In Whitton (2018), the way in which play corresponds with central educational aspects such as artefacts, organisation, attitudes and interaction of the teaching situation is aligned in detail. According to Andrew Walsh, higher education should provide 'opportunity to play and ensure its inherent attraction [is] obvious to learners' (Walsh, 2015, p. 84). Another example is Bogers and Sproedt (2012) who explored how a playful game can support complex processes of sense-making and sense-giving in an innovation course. Similar to our framepedagogy, they connect play - as a way of making sense - to relational knowledge and 'knowing-as-doing' (p. 92). They conclude that play is a mode of experience central to understanding 'the complex social dynamics that emerge when people have to deal with novelty' (p. 93). In that sense, education becomes dependent on playing together to fulfil educational ends in a context-specific, satisfying manner. These studies differ from the previous set we identify as 'separational', by valuing play on a broader pedagogical and human level. Here, play is embedded in ideas about how education should be approached, how experience should be formed and how humans engage with a world of content.

\section{Trending issues in Higher Education}

Margaret Lloyd and Nan Bahr (2015) recently reviewed the research presented in the Journal of Learning 
Design over the (then) last 10 years. Their article, titled 'What matters in Higher Education', identifies two recurring motifs: blended learning and authentic learning. Research studies on blended learning showed a high degree of research interest into variation and combinations of learning activities, as well as simulating work-place activities within the educational setting (p. 6). Studies with the motif of authentic learning were guided by a connection to the practical reality of what education was preparing for through 'an apprenticeship design where students are mentored in the workplace... a simulated reality design where the "real world" is simulated in face-to-face, online or blended environments [and] an enminding design which gains its authenticity through moving a student's way of thinking more in line with their discipline' (Lloyd \& Bahr, 2015, p. 8).

This tendency to value and investigate authentic learning aligns with a broader recognition of the need for education to resonate with the practice it seeks to educate towards. It also positions education as a method in service of supporting better and more qualified future experiences within a given discipline. The interest in and need for variation and authentic learning aligns with the theoretical and empirical narrative of our study. While our agenda is to nudge play into the realm of higher education, higher education is in recent years leaning more and more towards authenticity and explorative practices of educational sense-making, sustaining a broader argument of commonality across the above-mentioned study by Lloyd and Bahr as well as recent studies on simulation (Cox, Simpson, Letts, \& Cavanagh, 2015) and scenario-based teaching (Fougt \& Phillips, 2020).

\section{Conclusion}

Our transformative agenda, which we outlined in the beginning of this article, is about exploring ways to develop the pedagogical potential of play in the higher education setting of teacher training. In the theoretical part of our inquiry, we asked: What theoretical grounds can facilitate a shared perspective on higher education pedagogy and play? While the concept and practice of play continually filters into the domain of higher education, we argue that anchoring theories of play in pedagogy is indispensable, if we are sincerely interested in the different possibilities and qualities of educational sense-making. We aspire to provide a consistent and transparent system of interdependent concepts. One that corresponds rather than separates, and places education as a means for human life as a whole - that is of working, learning as well as playing throughout the lifespan. We propose sense-making as a useful central concept to forward this intention. It creates a basis of theoretical and practical correspondence between play, learning, experience and knowledge within a general pedagogy.

We found the common denominators of framing and sense-making to clear some of the theoretical cobwebs that exist between education and play. Playing and studying are equally about making sense of particular parts of human life. Disconnecting the two seems - from within our framework - incoherent and 
unnecessary, and therefore not an option. What Goffman's (1974) concept of framing shows us is that the meaning associated with the things around us dictates action. It quickly forms a frame of certain experiences, rather than others. The study's ambition was to develop a theoretical model that did not dismiss traditional educational values and practices but explores how these traditional frames can co-exist with others, such as playing. We then asked an empirical analytical question: How are the three frames of fact, toy and tool perceived by students, and how do the frames interact throughout the course?

Our observational data and student accounts tells us important things about frames of experience in relation to both play and education. By centering our analysis on sense-making, we allow traditional (fact-based) approaches to higher education and play to correspond at the level of pedagogy. In our observations, videoand audio material, we can identify the meta-frame (our way of performing a pedagogical design in relation to the students) as well as patterns of enactment and events in each of our three frames. Beyond the successful translation of our model into a teachers' training course, we discovered play to be a metacommunicative phenomenon that essentially consists of transforming and colouring social encounters as such. As shown, treating content as fact, toy and tool prompts certain involvement, but it is not what constitutes neither education nor playing. Treating content as either fact or tool can be playful, educational, both or neither. It depends on the meta-communication of the educational frame and the involvement it produces.

The way in which our general understanding of learning and teaching has transformed over the past twenty years is a subtle movement towards a greater correspondence with play. Simulation, scenario-based teaching, game-based learning, playful learning, inquiry-based teaching and learning all demand for some degree of 'make-believe' and playfulness. Even the practice of practicing is, according to Goffman, a subtle form of utilitarian make-believe (Goffman, 1974). Nonetheless, we have to be cautious not to disregard traditional frames of educational practices. It should not be about choosing authentic learning in opposition to 'the old ways'. Instead, we should work to build educational settings that combine both: an education that offers plenty and diverse frames of experience with the theories and practices of a given profession. We are convinced that a multiple-frame-approach to education, such as we introduce in this paper, holds great potential for corresponding with the needs of future professional settings. 


\section{References}

All European Academies. (2017). The European Code of Conduct for Research Integrity. Retrieved from https://allea.org/code-of-conduct/

Barab, S. (2006). Design-based research: a methodological toolkit for the learning scientist. In R. K. Sawyer (Ed.), The Cambridge handbook of the learning sciences (pp. 153-169). Cambridge: Cambridge University Press.

Barab, S. \& Squire, K. (2004). Design-based research: putting a stake in the ground. Journal of the Learning Sciences, 13, 1-14. doi:10.1207/s15327809j1s1301_1

Bateson, G. (1955). A theory of play and fantasy. Psychiatric Research Reports, 2, 39-51.

Biesta, G. (2010). 'This is My Truth, Tell Me Yours.' Deconstructive pragmatism as a philosophy for education. Educational Philosophy, and Theory, 42(7), 710-727. doi:10.1111/j.1469-5812.2008.00422.x

Biesta, G. (2014). Pragmatising the curriculum: bringing knowledge back into the curriculum conversation, but via pragmatism. Curriculum Journal, 25(1), 29-49. doi:10.1080/09585176.2013.874954

Biesta, G. J. J. \& Burbules, N. C. (2003). Pragmatism and educational research. Lanham, MD: Rowman and Littlefield.

Bjartveit, C., \& Panayotidis, L. E. (2017). Transforming early childhood educators' conceptions of 'dark play' and popular culture. Contemporary Issues in Early Childhood, 18(2), 114-26. doi:10.1177/1463949117714075.

Bogers, M., \& Sproedt, H. (2012). Playful collaboration (or not): using a game to grasp the social dynamics of open innovation in innovation and business education. Journal of Teaching in International Business, 23(2), 7597. doi:10.1080/08975930.2012.718702.

Brown, A. L. (1992). Design experiments: Theoretical and methodological challenges in creating complex interventions in classroom settings. Journal of the Learning Sciences, 2, 141-178. doi: 10.1207/s15327809j1s0202_2 Carlson, D. L., \& Clay, T. (2010). Evoking a spirit of play: M\&M's® stories and (un)real possibilities for teaching secondary literacy. Kappa Delta Pi Record, 46(4), 164-69. doi:10.1080/00228958.2010.10516547.

Clarke, A. E., Friese, C. \& Washburn, R. (2018). Situational analysis: grounded theory after the interpretive turn (2nd ed.). Thousand Oaks, CA: Sage.

Cox, J., Simpson, M., Letts, W., \& Cavanagh, H. (2015). Re-thinking microbiology/infection control education to enhance the practice-readiness of health professional students: More than just a curriculum issue. Journal of Learning Design, 8(1), 55-67. doi:10.5204/jld.v8i1.224

Dewey, J. (1916). Democracy and education. New York, NY: Macmillan.

Dewey, J. (1922). Human nature and conduct. An introduction to social psychology. New York, NY: Henry Holt and Company. 
Dewey, J. (1938). Experience and education. New York, NY: Macmillan.

Dewey, J. (2005). Demokrati og Uddannelse. Klim: København.

Fougt, S., \& Philipps, M. R. (2020). Teknologiforståelse: i et scenariedidaktisk perspektiv. Hans Reitzels Forlag.

Goffman, E. (1974). Frame analysis. An essay on the organization of experience. Cambridge, MA: Harvard University Press.

Goodwin, A. L., Low, E. L., Ng, P. T., Yeung, A. S., \& Cai, L. (2015). Enhancing playful teachers' perception of the importance of ICT use in the classroom: the role of risk taking as a mediator. Australian Journal of Teacher Education, 40(4), 133-50. doi:10.14221/ajte.2015v40n4.8

Haastrup, L. \& Knudsen, L. E. D. (2015). Teori- og praksisdidaktik. København: Forlaget Unge Pædagoger. Hartfield, P. (2010). Reinforcing constructivist teaching in advanced level biochemistry through the introduction of case-based learning activities. Journal of Learning Design, 3(3), 20-31. doi:10.5204/jld.v3i3.59

Hattie, J., \& Yates, G. C. R. (2014). Visible learning and the science of how we learn. Abingdon: Routledge.

Henricks, T. S. (2015). Play and the human condition. Champaign, IL: University of Illinois Press.

Kincheloe, J. L. (2005). On to the next level: continuing the conceptualization of the bricolage. Qualitative Inquiry, 11(3), 323-350. doi:10.1177/1077800405275056

Koupf, D. (2017). Proliferating textual possibilities: toward pedagogies of critical-creative tinkering. Composition Forum, 35. Retrieved from https://eric.ed.gov/?id=EJ1137815

Liang, M. Y. (2015). Play chronotopes: laughter-talk in peer group conversation. Classroom Discourse, 6(2), 158-172. doi:10.1080/19463014.2014.961091

Lloyd, M., \& Bahr, N. (2016). What matters in higher education a meta-analysis of a decade of learning design. Journal of Learning Design, 9(2), 1. doi:10.5204/jld.v9i2.280

Majgaard, G. (2014). The playful and reflective game designer. Electronic Journal of E-Learning, 12(3), 271-80. Retrieved from https://eric.ed.gov/?id=EJ1035649

Meyer, H. (2014). Was ist guter Unterricht? PADUA, 9, 75-83. doi:10.1024/1861-6186/a000170

Møller, H. (2020). Academic content as a toy: a pilot case study on play as studyation in higher education. The International Journal of Learning in Higher Education, 27(2), 53-62. doi:10.18848/2327-7955/CGP/v27i02/53-62 Møller, H. \& Skov, S. S. (2021). Scoping the Field of Play in Higher Education: Between separation and correspondence. Manuscript submitted for publication.

Munn, Z., Peters, M., Stern, C., Tufanaru, C., McArthur, A. \& Aromataris, E. (2018). Systematic review or scoping review? Guidance for authors when choosing between a systematic or scoping review approach. 
BMC Medical Research Methodology, 18(143). doi:10.1186/s12874-018-0611-x

Nørgård, R. T., Toft-Nielsen, C., \& Whitton, N. (2017). Playful learning in higher education: developing a signature pedagogy. International Journal of Play, 6(3), 272-82. doi:10.1080/21594937.2017.1382997

Pánek, J., Pászto, V., \& Perkins, C. (2018). Flying a kite: playful mapping in a multidisciplinary field-course. Journal of Geography in Higher Education, 42(3), 317-36. doi:10.1080/03098265.2018.1463975

Phillips, R. (2015). Playful and multi-sensory fieldwork: seeing, hearing and touching New York. Journal of Geography in Higher Education, 39(4), 617-29. doi:10.1080/03098265.2015.1084496

Reeves, T. (2006). Design research from a technology perspective. In J. V. D. Akker, K. Gravemeijer, S. McKenney \& N. Nieveen (Eds.), Educational Design Research. (pp. 52-66). London: Routledge.

Schön, D. A. (1991). The reflective practitioner - how professionals think in action. Farnham: Ashgate Publishing Group.

Sfard, A. (1998). On two metaphors for learning and the danger of choosing just one. Educational Researcher, 27(2), 4-13. doi:10.2307/1176193

Souto-Manning, M. (2011). Playing with power and privilege: theatre games in teacher education. Teaching and Teacher Education, 27(6), 997-1007. doi10.1016/j.tate.2011.04.005

Stenner, P. (2012). Pattern. In C. Lury \& N. Wakeford (Eds.), Inventive methods: the happening of the social. (pp. 136-146). Abingdon: Routledge.

Thorsted, A. C., Bing, R. G., \& Kristensen, M. (2015) Play as mediator for knowledge-creation in problem based learning. Journal of Problem Based Learning in Higher Education, 3(1), 63-77. doi:10.5278/ojs.jpblhe.v3i1.1203.

Tricco, A. C., Antony, J., Zarin, W., Strifler, L., Ghassemi, M., Ivory, J., Perrier, L., Hutton, B., Moher, D., \& Straus, S. E. (2015). A scoping review of rapid review methods. BMC Medicine, 13, 224. doi:10.1186/s12916015-0465-6

van As, A. J., \& Excell, L. (2018). Strengthening early childhood teacher education towards a play-based pedagogical approach. South African Journal of Childhood Education, 8(1), 1-10. doi:10.4102/sajce.v8i1.525 Varvarigou, M. (2017). Promoting collaborative playful experimentation through group playing by ear in higher education. Research Studies in Music Education, 39(2), 161-76. doi:10.1177/1321103X17704000 Walsh, A. (2015). Playful information literacy: play and information literacy in higher education. Nordic Journal of Information Literacy in Higher Education, 7(1), 80-94. doi:10.15845/noril.v7i1.223

Walsh, G. \& Fallon, J. (2019). What's all the fuss about play? Expanding student teachers' beliefs and understandings of play as pedagogy in practice. Early Years. doi:10.1080/09575146.2019.1581731 
Whitton, N. (2018). Playful learning: tools, techniques, and tactics. Research in Learning Technology, $26,1-12$. doi:10.25304/rlt.v26.2035 